\title{
507
}

\section{XXV.-On the Products of the Decomposition of Castor Oil. No. 2. The Distillation of Sodium Ricinoleate.}

By E. NEISON.

According to Bouis (Compt. rend., vol. xli, p. 603), when sodium ricinoleate free from excess of sodium hydrate is distilled, the oily distillate consists of octylic aldehyde, or rather of methyl-hexyl ketone (methyl-œnanthol), mistaken by him for its isomeride the aldehyde. Städeler, however, obtained by this method only heptylic aldehyde (œnanthol) (Jour. für prackt. Chem., vol. lxxii, p. 241). Both agree that no sebacic acid is obtainable from the residue.

It was considered necessary to determine if possible the true nature of the reaction, and the cause of decided difference in the product obtained. For the purpose, therefore, of elucidating the question, the process adopted by Bouis was repeated as follows:-

Seventy grams of sodium hydrate were dissolved in five times their weight of water, and whilst boiling, three hundred and fifty grams of castor oil were stirred in. The soap was separated by the addition of a litre of sodium chloride solution, and the whole well boiled together. The resulting soap obtained was submitted to powerful pressure, and fused to drive off moisture, until it began to decompose. As thus obtained, it formed a hard white semi-transparent mass, apparently free from any trace of free sodium hydrate; it was distilled in small quantities from a copper flask by the direct application of the flame of a powerful bunsen, whereby thirty grams of a clear colourless limpid oil was obtained, which was separated from the accompanying aqueous distillate, dried over calcium chloride, and fractionally distilled.

Below $172^{\circ}$ only 2 grams of oil came over, the thermometer rapidly rising to that point; and between $172^{\circ}$ and $173^{\circ}, 85$ per cent. came over, the residue distilling between $173^{\circ}$ and $176^{\circ}$. The fraction distilling between $172^{\circ}$ and $173^{\circ}$ was collected separately, and consisted of 26 grams of a perfectly colourless, limpid oil, having the odour and physical properties of methyl-hexyl ketone. No trace of heptylic aldehyde existed in the small portion which boiled below $172^{\circ}$, and con. sisted of the ketone mixed with a trace of a liquid boiling very much lower, and probably consisting of octylene. The portion boiling between $173^{\circ}$ and $176^{\circ}$ consisted likewise chiefly of the ketone, mixed probably with a trace of octylic alcohol, as a small quantity of sebacio acid was obtained from the residue. This latter gave a very small quantity of sebacic acid and a large quantity of the oily resin usually obtained in the preparation of sebacic acid.

The accuracy of the results obtained by Bouis is therefore entirely 
confirmed, the soap used being prepared in the same manner as that employed by him.

It became necessary therefore to investigate the cause of the very different reaction obtained by Städeler, and it was at once apparent that it lay probably in the different methed of preparing the castor soap. Städeler does not give the details of the manner in which he prepared his dry sodium ricinoleate; but it appeared probable that the amounts of castor oil and sodium hydrate necessary to form it were boiled with water and evaporated nearly to dryness.

Accordingly 220 grams of castor oil were boiled with 30 grams of sodium hydrate dissolved in 200 grams of water. The soap was then separated by the addition of one litre of strong sodium chloride solution, the whole well boiled and allowed to cool. The soap was washed with water, submitted to powerful pressure, and fused to drive off moisture until it began to decompose. The resulting yellowish white mass, which appeared to contain some unsaponified oil, was distilled from a copper flask as before, but with a somewhat gentler heat. Dense white fumes appeared the whole time, and the distillate consisted of a dark brown oil floating on a watery layer.

By this means 40 grams of a clear dark brown oily liquid, having a very powerful odour was obtained, and after drying over calcium chloride, fractionally distilled. Below $140^{\circ}$ only 7 per cent. came over, and between $140^{\circ}$ and $165^{\circ}$ about 10 grams, and between $165^{\circ}$ and $200^{\circ}$ about 8 grams more. The remainder, nearly 50 per cent., consisted of a mixture of neutral oils and fatty acids boiling above $200^{\circ}$, among which œnanthylic acid predominated. The portions boiling below $200^{\circ}$ were mixed and redistilled. Between $120^{\circ}-150^{\circ}$ about 30 per cent. was found to distil, and consisted chiefly of an oil uniting at once with a strong solution of acid sodium sulphite to a white pulpy mass. Between $150^{\circ}-160^{\circ}$, but chiefly at $155^{\circ}-157^{\circ}$, nearly 60 per cent. came over, which also combined instantly with a concentrated solution of the acid sodium sulphite to a white semi-solid mass. Between $160^{\circ}-170^{\circ}$ the remainder came over, and likewise united with the acid sodium sulphite.

The first two portions were mixed, and after washing with water and alcohol, decomposed by sodium hydrate solution; the resulting oil being dried and distilled. Ninety per cent. distilled between $155^{\circ}-$ $157^{\circ}$, and possessed all the well-marked characteristic properties of heptylic aldehyde (œnanthol), solidifying at once, with evolution of heat when shaken with a concentrated solution of the acid solution sulphite.

The portion distilling between $160^{\circ}-170^{\circ}$ was also found to consist chiefly of heptylic aldehyde, mixed perhaps with a trace of the methyl-hexyl ketone. 
The residue in the flask dissolved easily in hot water, but gave no trace of sebacic acid, and agreed in appearance with the description given by $\mathrm{Städeler}$ of the residue obtained by him. The gas given off during the reaction consisted mainly of hydrogen with a little carbonic anhydride.

As Städeler purified his product by direct treatment with acid sodium sulphite solution, and then separated the heptylic aldehyde by alkalis, the acids found accempanying the aldehyde would be lost; and this would account for his not noticing them. The general agreement of the two results is confirmatory of the supposition that Städeler prepared his dry sodium ricinoleate in a similar marner.

Upon analysis, neither soap was found to be perfectly homogeneous, but the amount of sodium was somewhat variable. On the whole, however, the soap, as made by the first method, contained a small excess of sodium above the theoretical amount, whilst in the second sample a deficiency was found: and to this difference in the amount of sodium present must the variation be attributed.

The result, however, in the first case shows that Städeler's hypothesis that the formation of methyl-hexyl ketone is accompanied by the formation of sebacic acid is not accurate, and renders it probable that the formation of sebacic acid depend on that of the well-known castor oil alcohol, isoctylic.

It would appear therefore, in conclusion, that the statements of Bouis and Städeler are perfectly accurate, and that their apparently contradictory nature arises from a difference in the nature of the soap used. 